\title{
Appropriate Cardiovascular Prevention is Not Implemented in Diabetic Hypertensive Patients Treated in General Practice
}

\author{
Juha Varis $^{*}$, , Heljä Savola ${ }^{1}$, RistoVesalainen ${ }^{2}$ and Ilkka Kantola ${ }^{1}$ \\ ${ }^{I}$ Department of Medicine, Turku University Hospital, FI-20520 Turku, Finland \\ ${ }^{2}$ Pulssi Medical Center, FI-20100 Turku, Finland
}

\begin{abstract}
Introduction of guidelines and more effective cardiovascular prevention have taken place in Finland. This study clarified whether treatment of the Finnish diabetics reflects these changes. Antihypertensive, lipemic and diabetic care of diabetics in Finnish general practice was analyzed nationwide by using a questionnaire. Subjects that participated in the study were consecutive hypertensive patients that had met their general practitioners during a given week in 2006. Only $9.4 \%$ of the diabetics reached the blood pressure target below $130 / 80 \mathrm{mmHg}$. Fifty-six \% of the patients reached the target of glycocylated haemoglobin (GHbA1c) below 7.0\%. The low density lipoprotein (LDL) cholesterol was below 2.5 $\mathrm{mmol} / 1(96.7 \mathrm{mg} / \mathrm{dl})$ in $43.9 \%$ of the patients. In multivariate model, young age and high GHbA1c associated with high diastolic blood pressure. Fewer patients with GHbA1c $>7 \%$ reached the target pressure below 140/90 mmHg than those with GHbA1c $\leq 7.0 \%(\mathrm{p}<0.05)$, but no difference was found if the target was below 130/80 $\mathrm{mmHg}$. Neither the number of antihypertensive agents nor home blood pressure monitoring did affect the blood pressure. Blood pressure control of the treated Finnish diabetics was poor. Metabolic targets were more commonly reached than the blood pressure target but still too seldom. The cardiovascular prevention is not implemented in Finnish diabetic patients treated in general practice.
\end{abstract}

Keywords: Hypertension, general, diabetes, pharmacologic (drug), primary care issues.

\section{INTRODUCTION}

Half of the Finnish men aged 35-64 years and one third of women in the same age group are hypertensive [1]. More than half a million Finns received special reimbursement for antihypertensive drug treatment in the year 2006 [2]. Also about half a million patients suffer from diabetes in Finland [3]. The blood pressure levels in the general Finnish population have decreased significantly since the year 1972 up to the year 2002 [1]. Thereafter no decrease has been noticed, probably because the frequency of obesity and also alcohol consumption have increased [4].

Diabetics are twice as likely to experience cardiovascular events as non-diabetics [6]. Majority of the Finnish diabetics with mild to moderate hypertension have at least one additional cardiovascular risk factor $[3,7,8]$. According to the European Society of Hypertension guidelines the blood pressure treatment target for diabetics is set to $\leq 130 / 80$ $\mathrm{mmHg}$ [5] as it is also in the latest Finnish Diabetic Guidelines [3]. Hypertensive patients show higher mean serum cholesterol concentrations and higher body mass index compared to normotensive population $[7,9]$. Due to this accumulation of risk factors leading to increased risk of developing cardiovascular disease, poorly treated hypertension and hyperlipidemia are likely to be especially harmful among diabetics.

In addition to national guidelines, changes supporting more effective antihypertensive treatment have been pre-

*Address correspondence to this author at the Department of Medicine, Turku University Hospital, FI-20520 Turku, Finland; Tel: 35823130657 ; Fax: 3582 2613030; E-mail: juha.varis@tyks.fi sented during the last years in Finland. Fixed-dose drug combinations and new, better tolerated antihypertensive drugs have been introduced. The prices of the older antihypertensive drugs have fallen and home blood pressure measurement has become increasingly available. This study clarified whether cardiovascular risk factor treatment of the Finnish diabetics in the general practice reflects these recent changes.

\section{METHODS}

The patients were recruited among hypertensive patients visiting general practitioner (GP) offices during autumn 2006. Altogether 72 GPs from all five university hospital districts of Finland were asked to collect data from all drug treated hypertensive patients aged 18 years or above visiting their office during a given week. GPs informed patients about the study and received written consent from those who agreed to participate in the study. The study was accepted by the common ethics committee of Turku University and Hospital District of South-western Finland.

GPs filled in the study questionnaire which contained data on age, sex, height, weight, smoking habits, latest blood lipid and glucose values as well as measured blood pressure (BP). Mercury sphygmomanometer was used to measure systolic and diastolic (Korotkoff sounds, phase V) BP according to the Finnish Hypertension Guidelines [10]. The time BP was measured varied between the patients as it took place during the ordinary out-patient visit at any time during the normal working hours (from 8 am to $4 \mathrm{pm}$ ) of the GPs. The GPs were also asked to collect data of other cardiovascular diseases, medication and the method the patients 
Table 1. Characteristics of the Diabetic Patients

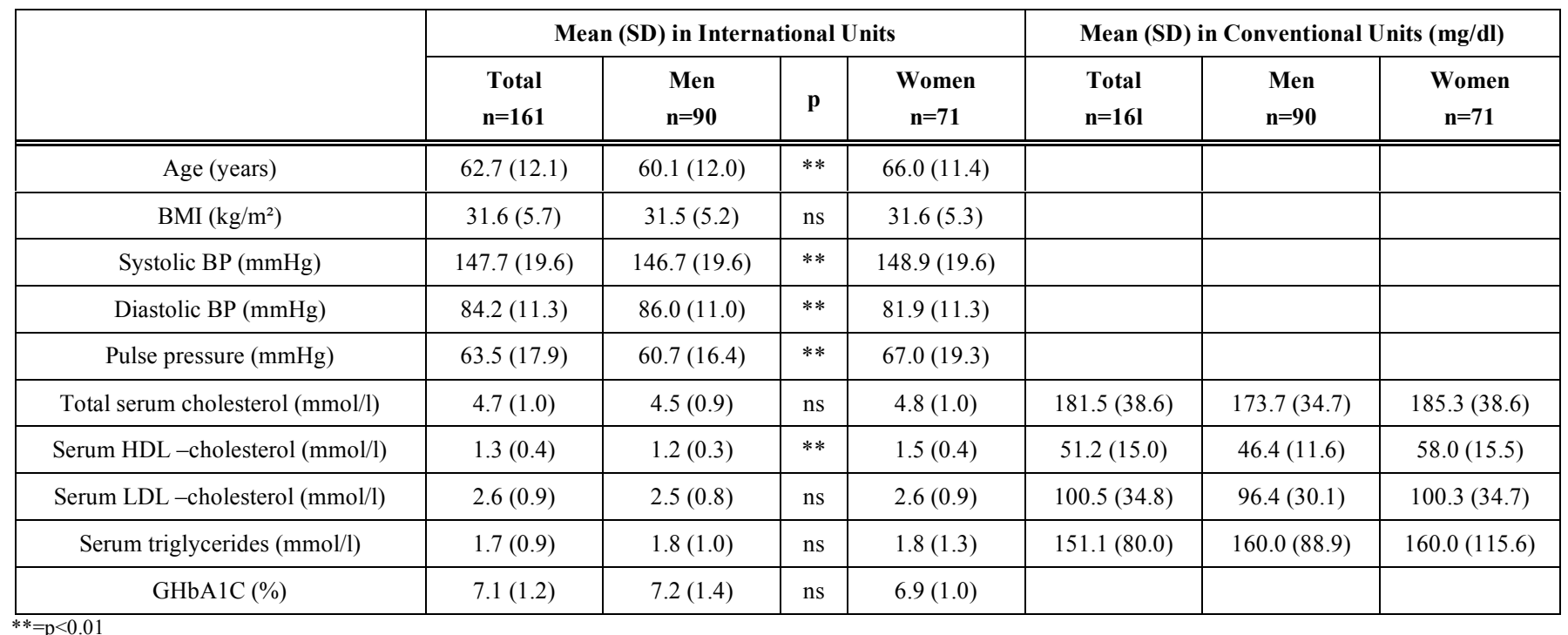

used to monitor blood pressure. Diabetes was defined as either fasting plasma glucose level over $7.0 \mathrm{mmol} / 1(125,4$ $\mathrm{mg} / \mathrm{dl}$ ) on two different occasions, two-hour plasma glucose level in the two-hour oral glucose tolerance test over 11.0 $\mathrm{mmol} / \mathrm{l}(197,0 \mathrm{mg} / \mathrm{dl})$ or the use of at least one antidiabetic agent.

The original study population consisted of 358 drugtreated hypertensive men and 357 women [11]. Altogether 191 (182 patients with type 2 diabetes and nine with type 1 diabetes, 100 men and 91 women) antihypertensive drugtreated diabetic patients were noticed among them and further analyzed for this study.

\section{STATISTICS}

The continuous variables are expressed as mean (SD). Database management and statistical analysis were performed using SPSS software, version 16.0. Group differences in continuous variables were assessed with unpaired Student's t test or one way analysis of variance as appropriate. Chi-square test was used for the comparison of two proportions. The cut-off level for statistical significance was set at P-value $<0.05$. The normal distribution of the continuous variables were confirmed using Shapiro-Wilks' test of normality. The significance of correlation between variables was determined by Pearson's correlation analysis. Multivariate stepwise linear regression analysis was applied to assess independent predictors of the variables of interest, performed where the univariate $\mathrm{p}$ value was $<0.05$.

\section{RESULTS}

Of the original 191 diabetic patients, all necessary data was obtainable in 161 cases. Basic data of these patients is presented in Table 1. Compared to women, men had significantly lower systolic BP, higher diastolic BP and lower HDL-cholesterol.

Majority of the diabetics $(93 \%, 156 / 168)$ had the body mass index $(\mathrm{BMI})>25 \mathrm{~kg} / \mathrm{m}^{2}, 59 \%$ had $(99 / 168)$ BMI $>30$ $\mathrm{kg} / \mathrm{m}^{2}$ and $7 \%(12 / 168) \mathrm{BMI}>40 \mathrm{~kg} / \mathrm{m}^{2}$. The GHbA1c data was obtainable from 175 patients and LDL-cholesterol data from 180 patients (Table 1). Patients with type 2 diabetes had mean GHbA1c of $7.0(1.2) \%(n=168)$ and patients with type 1 diabetes $8.4(1.6) \%(n=7)$. In 66 patients $(37.7 \%)$ GHbA1c was below $6.5 \%$ and in 98 patients $(56.0 \%)$ below $7.0 \%$. LDL- cholesterol was below $2.0 \mathrm{mmol} / 1(77.3 \mathrm{mg} / \mathrm{dl})$ in 43 patients $(23.9 \%)$ and below $2.5 \mathrm{mmol} / 1(96.7 \mathrm{mg} / \mathrm{dl})$ in 79 patients (43.9\%). Only 67 patients $(34.9 \%$ ) used HMGCoA reductase inhibitors (statins).

Of all patients taking antihypertensive medications $(n=191), 34$ patients $(17.8 \%)$ had BP less than $140 / 80$ $\mathrm{mmHg}$ and 18 patients $(9.4 \%)$ less than $130 / 80 \mathrm{mmHg}$. Systolic BP exceeded $140 \mathrm{mmHg}$ in 112 patients $(58.6 \%)$ and $130 \mathrm{mmHg}$ in 153 patients $(80.1 \%)$. Fifty-six patients (29.3\%) had diastolic BP less than $80 \mathrm{mmHg}$.

The mean systolic blood pressure of the patients with GHbA1c $\leq 7.0 \%$ was $147.2(20.3) \mathrm{mmHg}$ and of the patients with GHbA1c $>7.0 \% 146.8$ (24.5) $\mathrm{mmHg}(\mathrm{p}=0.963)$. The corresponding diastolic blood pressure values were 83.7 (12.2) $\mathrm{mmHg}$ and 85.6 (12.0) $\mathrm{mmHg}(\mathrm{p}=0.412)$. Fewer patients reached blood pressure below 140/90 $\mathrm{mmHg}$ among the patients with GHbA1c $>7.0 \% \quad(\mathrm{p}<0.05)$ but no significant difference was noticed when the target pressure was set to below 130/80 $\mathrm{mmHg}$ (Table 2).

Table 2. The Number (\%) of the Diabetics Patients having Reached Target Blood Pressure According to their HbA1C -Concentration

\begin{tabular}{|c|c|c|c|}
\hline & $\begin{array}{c}\text { All diabetics } \\
(\mathbf{n}=\mathbf{1 7 5})\end{array}$ & $\begin{array}{c}\text { HbA1C } \leq 7.0 \% \\
(\mathbf{n}=\mathbf{1 0 8})\end{array}$ & $\begin{array}{c}\text { HbA1C }> \\
\mathbf{7 . 0 \%}(\mathbf{n}=\mathbf{6 7})\end{array}$ \\
\hline \hline $\begin{array}{c}<140 / 90 \\
\mathrm{mmHg}\end{array}$ & $56(32.0)$ & $39(36.1)^{*}$ & $17(25.4)^{*}$ \\
\hline $\begin{array}{c}<130 / 80 \\
\mathrm{mmHg}\end{array}$ & $17(9.7)$ & $12(11.1) \mathrm{ns}$ & $5(7.5) \mathrm{ns}$ \\
\hline$*=\mathrm{p}<0.05$ & \multicolumn{3}{|l}{} \\
\hline
\end{tabular}

No significant difference in blood pressure was observed in patients using one, two, three or more than three 
antihypertensive drugs (Table 3). Blood pressure was below $140 / 80 \mathrm{mmHg}$ in 10 patients (19.6\%) using one, in 8 patients $(12.5 \%)$ using two, in 9 patients $(16.7 \%)$ using three and in 4 patients $(18.2 \%)$ using more than three antihypertensive drugs.

Table 3. Mean Blood Pressure (SD) in Patients Using Either One, Two, Three or More than Three Anti-hypertensive Drugs

\begin{tabular}{|c|c|c|}
\hline & $\begin{array}{c}\text { Systolic BP } \\
(\mathbf{m m H g})\end{array}$ & $\begin{array}{c}\text { Diastolic Bp } \\
(\mathbf{m m H g})\end{array}$ \\
\hline \hline One antihypertensive drug (n=51) & $145.3(19.6) \mathrm{ns}$ & $86.1(11.8) \mathrm{ns}$ \\
\hline Two antihypertensive drugs (n=64) & $149.8(21.0) \mathrm{ns}$ & $86.7(11.1) \mathrm{ns}$ \\
\hline $\begin{array}{c}\text { Three antihypertensive drugs } \\
(\mathrm{n}=54)\end{array}$ & $146.2(18.3) \mathrm{ns}$ & $82.8(11.5) \mathrm{ns}$ \\
\hline $\begin{array}{c}\text { More than three antihypertensive } \\
\text { drugs }(\mathrm{n}=22)\end{array}$ & $151.9(21.2) \mathrm{ns}$ & $81.7(13.0) \mathrm{ns}$ \\
\hline
\end{tabular}

Nine patients had blood pressure below 130/80 $\mathrm{mmHg}$, LDL-cholesterol below $2.5 \mathrm{mmol} / 1 \quad(96.7 \mathrm{mg} / \mathrm{dl})$ and GHbA1c below $7.0 \%$. With three patients, blood pressure and LDL-cholesterol targets were reached but GHbA1c was over $7.0 \%$.

Diastolic blood pressure was higher (88.0 (12.8) vs. 83.5 (11.2) $\mathrm{mmHg}, \mathrm{p}=0.015)$ in 62 patients with serum triglyceride concentration over $2.0 \mathrm{mmol} / \mathrm{l}(177.8 \mathrm{mg} / \mathrm{dl})$. Also in 41 patients with high density lipoprotein (HDL) cholesterol $\leq 1.0 \mathrm{mmol} / 1(38.6 \mathrm{mg} / \mathrm{dl})$ similar results were observed (88.4 (11.2) vs. 84.0 (12.0) $\mathrm{mmHg}, \mathrm{p}=0.04)$, when compared with the remaining patients. No significant difference was observed in systolic blood pressure. Only 4 patients $(6.5 \%)$ with serum triglyceride concentration over $2.0 \mathrm{mmol} / \mathrm{l}(177.8 \mathrm{mg} / \mathrm{dl})$ and 5 patients (12.2\%) with HDL- cholesterol below $1.0 \mathrm{mmol} / 1 \quad(38.6 \mathrm{mg} / \mathrm{dl})$ had blood pressure below 130/80 $\mathrm{mmHg}$.

One hundred and six patients (106) (55.5\%) used home blood pressure monitoring regularly. No significant difference in blood pressure was observed between patients using home blood pressure monitoring $(n=106)$ and the patients $(\mathrm{n}=82)$ not using it (systolic BP 148.1 (23.8) vs. 144.9 (18.6) $\mathrm{mmHg}, \mathrm{p}=0.152$ and diastolic BP 85.9 (12.1) vs. 83.4 (11.6) $\mathrm{mmHg}, \mathrm{p}=0.330)$.

In bivariate correlation analysis, systolic BP of the patients did not correlate to any demographic or laboratory parameters (Table 4a). Diastolic BP correlated positively with male gender, weight, BMI, LDL-cholesterol and GHbA1c, and negatively with age and HDL- cholesterol. According to the stepwise multivariate analysis, only young age and high GHbA1c remained as significant predictors for high diastolic blood pressure (Table $\mathbf{4 b}$ ).

Of all demographic, laboratory and BP variables tested, GHbA1c correlated only with diastolic $(\mathrm{r}=0.225, \mathrm{p}=0.003)$ blood pressure in a bivariate model.

\section{DISCUSSION}

The cardio-metabolic control of the Finnish diabetic patients was poor in the year 2006. Only about $9 \%$ of the patients reached BP below 130/80 $\mathrm{mmHg}$. Results are in parallel with recent papers highlighting difficulties in reaching the BP targets, especially in patients with metabolic syndrome and/or diabetes [12, 13]. Hyperglycemia and hypercholesterolemia were more effectively treated than blood pressure, but the proportion of patients reaching the treatment targets remained low. GHbA1c was below $7.0 \%$ in about half of the patients. Only one fourth of the patients reached LDL-cholesterol target below $2.0 \mathrm{mmol} / 1$ (77.3 $\mathrm{mg} / \mathrm{dl}$ ) and $44 \%$ of the patients reached target below 2.5

Table 4a. Correlations between Blood Pressure. Glycemic Parameters. Demographic Data and Laboratory Findings $($ SBP $=$ Systolic Blood Pressure. DBP=Diastolic Blood Pressure)

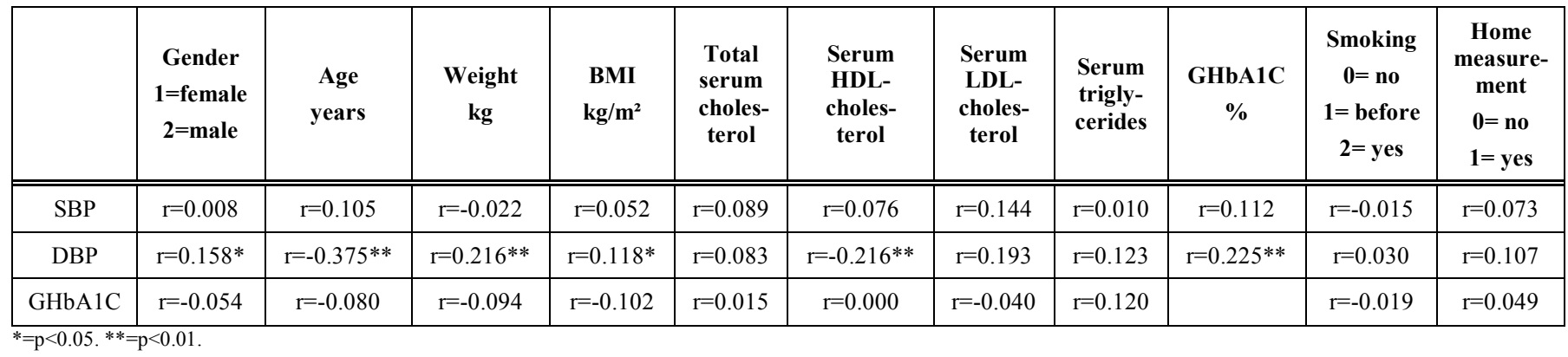

Table 4b. Stepwise Multiple Linear Regression Model for Diastolic Blood Pressure (Standardized Regression Coefficient. p-Value)

\begin{tabular}{|c|c|c|c|c|c|c|c|}
\hline & $\begin{array}{c}\text { Gender } \\
\mathbf{1 = f e m a l e} \\
\mathbf{2 = m a l e}\end{array}$ & $\begin{array}{c}\text { Age } \\
\text { years }\end{array}$ & $\begin{array}{c}\text { Weight } \\
\mathbf{k g}\end{array}$ & $\begin{array}{c}\text { BMI } \\
\mathbf{k g} / \mathbf{m}^{2}\end{array}$ & $\begin{array}{c}\text { Serum } \\
\text { HDL-cholesterol }\end{array}$ & $\begin{array}{c}\text { Serum } \\
\text { LDL-cholesterol }\end{array}$ & $\begin{array}{c}\text { GHbA1C } \\
\mathbf{\%}\end{array}$ \\
\hline \hline Diastolic BP. mmHg & $\begin{array}{c}0.046 \\
\mathrm{p}=0.569\end{array}$ & $\begin{array}{c}-0.393 \\
\mathrm{p}=0.0001\end{array}$ & $\begin{array}{c}0.094 \\
\mathrm{p}=0.257\end{array}$ & $\begin{array}{c}0.120 \\
\mathrm{p}=0.126\end{array}$ & $\begin{array}{c}-0.143 \\
\mathrm{p}=0.069\end{array}$ & $\begin{array}{c}0.012 \\
\mathrm{p}=0.155\end{array}$ \\
$\mathrm{p}=0.002$ \\
\hline
\end{tabular}


$\mathrm{mmol} / \mathrm{l}(96.7 \mathrm{mg} / \mathrm{dl})$. Only $4.7 \%$ of the patients reached ideal cardio-metabolic control.

Our data was obtained from GPs as a cross section of their normal, daily work. This mode of data collection may result in underestimation of the overall severity of hypertension because the patients who visit GPs regularly are usually those who are most committed to their treatment. However, it may also overestimate the severity of hypertension because of the potential error caused by the white coat effect. Questionnaire -based data collection is prone to reporting error leading to underestimation of other major cardiovascular risk factors, especially smoking. The time of the measurement of the BP varied which adds some uncertainty in the results. Synchronization of the BP measurement time was impossible considering the mode of the study material collection. Nevertheless, GPs share the same problems in their everyday work. The present study looks at the problem of hypertension and its treatment from the perspective of the GP with all its pros and cons.

There were only few patients with type 1 diabetes in our study. Thus discussion mostly concentrates on patients with type 2 diabetes. In our study high GHbAlc concentration independently predicted high diastolic blood pressure. In support of that also fewer patients with GHbA1c concentration over $7.0 \%$ reached the blood pressure target below $140 / 90 \mathrm{mmHg}$. No significant difference was observed in those patients reaching the target below 130/80 $\mathrm{mmHg}$, probably due to the small number of the patients reaching that level. One possible explanation for the observed higher diastolic pressure in patients with higher GHbA1c could be the higher peripheral resistance in patients with poor glucose control [14].

In previous studies [12, 13], hypertriglyceridemia and low HDL cholesterol were associated with resistance to antihypertensive treatment. Similarly in our study, diastolic blood pressure was higher in the diabetics with high triglyceride concentration or low HDL-cholesterol. However, the proportion of patients reaching blood pressure targets remained low even in patients with good glycemic control and normal HDL-cholesterol and triglyceride concentrations.

Isolated risk factors like hyperglycaemia, obesity and dyslipidemia are markers of poor diabetic control and often clustered as metabolic syndrome. The occurrence of obesity is increasing in Finland [15]. Also the vast majority of our diabetic patients were obese. BMI and weight were associated with diastolic blood pressure, but not with systolic blood pressure in our study. Roughly two thirds of the study patients had metabolic syndrome although waist circumference was not measured in this study. It is also noteworthy that almost $10 \%$ of the diabetics had BMI over $40 \mathrm{~kg} / \mathrm{m}^{2}$. This observation suggests that all possible efforts to prevent obesity are needed to cut down the continuing increase in the incidence of diabetes [15-17].

One possible explanation for the disappointing control of hypertension may be that both the patients and their GPs still have a "one disease" orientation and less attention is paid to reduce all modifiable cardiovascular risk factors. In this study only about $5 \%$ of the patients reached ideal cardiovascular control. Glycemic control with its easy, exact and "white coat effect" -free blood glucose measurements is perhaps felt fundamental by the patients and GPs, and has superseded the troublesome and more difficult blood pressure control. We found the low proportion of patients reaching LDL-cholesterol target and a small number of patients on statin treatment surprising, because LDL target can nowadays be reached in nearly every patient with modern cholesterol lowering medication. The education of primary care GPs and information targeted to patients should therefore more clearly stress the importance of total cardiovascular risk and effective treatment of all modifiable cardiovascular risk factors in diabetics [18].

According to the meta-analysis by Law [19] increasing the number of antihypertensive drugs with different modes of action markedly improves the antihypertensive effect as compared to doubling of a dose of a single antihypertensive drug. However, in this study no difference between the patients using one to three antihypertensive drugs was observed. Less than one fifth of the patients in different groups reached BP target below 140/80 $\mathrm{mmHg}$. In this context we used this BP target because very few patients achieved the target below 130/80 $\mathrm{mmHg}$. Our results clearly show that it is especially difficult to reach systolic blood pressure below $140 \mathrm{mmHg}$ in diabetic patients. Previous studies have estimated that at least $80 \%$ of the patients using three or more antihypertensive drugs should reach the target pressure [19]. However, in our study less than $20 \%$ of the patients using three or more antihypertensive drugs reached the BP target. This may be caused by several factors. The compliance of antihypertensive treatment is likely to be poorer in the real life than in the clinical studies. Secondly, the unselected patients studied here may have more resistant hypertension and they are likely to be less intensively followed up by their GPs than if the patients are included in a controlled clinical study. Thirdly, confounding external factors typically common in Finland, such as high alcohol consumption or frequent use of other agents increasing blood pressure, such as non-steroidal anti-inflammatory drugs or liquorice, may have played a role. Finally, increased arterial stiffness of the diabetic patients may resist especially the systolic pressure decrease caused by antihypertensive drugs [20]. Nevertheless, the poor BP control also in patients with only one or two antihypertensive drugs suggests that the treating GPs were willing to accept suboptimal BP control without intensifying the treatment further.

Home blood pressure monitoring is nowadays increasingly common, and also in this study more than half of the patients used it regularly. Home blood pressure monitoring has been associated with better BP control and good prognosis [10]. However, in our study no difference in BP control was observed between those using home measurement and those not using it. It is, of course, possible that the GPs had recommended home measurement more often to the patients with more severe hypertension.

\section{SUMMARY}

In 2006, fewer than one tenth of the Finnish diabetics using antihypertensive drug treatment reached the BP target $<130 / 80 \mathrm{mmHg}$ in primary care. Although glycemic and LDL-cholesterol targets were more often reached, only about half of the patients had GHbA1c $<7.0 \%$ and less than half of 
the patients had LDL-cholesterol $<2.5 \mathrm{mmol} / 1(96.7 \mathrm{mg} / \mathrm{dl})$. Only one third of the patients used cholesterol lowering medication. Especially antihypertensive treatment, but also glycemic control and treatment of hyperlipidemia should be intensified to reduce the cardiovascular risk in Finnish diabetics. Public health decision makers should also consider intensification of current antihypertensive life-style modification programs.

\section{ACKNOWLEDGEMENTS}

We thank LeirasFinland Oy for organizing the delivery and collection of the study questionnaires and Turku University Hospital for a grant enabling this study. We thank Inkeri Suomela for revising the English of this article.

\section{REFERENCES}

[1] Kastarinen MJ, Antikainen RL, Laatikainen TK, et al. Trends in hypertension care in eastern and south-western Finland during 1982-2002. J Hypertens 2006; 24: 829-36.

[2] Finnish Statistics on Medicines 2006. Lääkelaitos ja Kansaneläkelaitos. Edita Oy. Helsinki 2007.

[3] The Finnish Current Care Guidelines: Diabetes. Duodecim 2002; 118: 110-26. First update. 2005; 121: 1-22.

[4] Peltonen M, Harald K, Männistö S, et al. Kansallinen FINRISKI 2007 terveystutkimus. Tutkimuksen toetutus ja tulokset. KTLNational Public Health Institute, Finland. Department of Health Promotion and Chronic Disease Prevention. B34/2008.

[5] European Society of Hypertension and European Society of Cardiology. 2007 Guidelines for the Management of Arterial Hypertension. J Hypertens 2007; 25: 1105-87.

[6] Deedwania P. Hypertension and Diabetes, new therapeutic options. Arch Intern Med 2000; 160: 1585-94.

[7] Kastarinen M, Tuomilehto J, Vartiainen E, et al. Trends in lipid levels and hypercholesterolemia in hypertensive and normotensive Finnish adults from 1982 to 1997. J Intern Med 2000; 247: 53-62.
[8] Kastarinen M, Tuomilehto J, Vartiainen E, Jousilahti P, Nissinen A, Puska P. Smoking trends in hypertensive and normotensive Finns during 1982-1997. J Hum Hypertens 2002; 16: 299-303.

[9] Kastarinen MJ, Nissinen AM, Vartiainen EA, et al. Blood pressure levels and obesity trends in hypertensive and normotensive Finnish population from 1982 to 1997. J Hypertens 2000; 18: 255-62.

[10] The Finnish Current Care Guidelines: Hypertension. Duodecim 2002; 118: 110-26. First update. 2005: 121: 1-22.

[11] Varis J, Savola H, Vesalainen R, Kantola I. Treatment of hypertension in Finnish general practice seems unsatisfactory despite evidence-based guidelines. Blood Pressure 2009; 18: 62-7.

[12] Kjeldsen SE, Naditch-Brule L, Perlini S, Zidek W, Farsang C. Increased prevalence of metabolic syndrome in uncontrolled hypertension across Europe: the Global Cardiometabolic Risk Profile in Patients with hypertension disease survey. J Hypertens 2008; 26: 2064-70.

[13] Zidek W, Naditch-Brüle L, Perlini S, Farsang C, Kjeldsen SE. Blood pressure control and components of the metabolic syndrome: the GOOD survey. Cardiovasc Diabetol 2009; 8: 51.

[14] Levy BI, Schiffrin EL, Mourad JJ, et al. Impaired tissue perfusion a pathology common to hypertension, obesity and diabetes mellitus. Circulation 2008; 118: 968-76.

[15] Lahti-Koski M, Seppänen-Nuijten E, Männistö S, et al. Twentyyear changes in the prevalence of obesity among Finnish adults Obes Rev 2010; 11(3): 171-6.

[16] Gordon-Larsen P, The NS, Adair LS. Longitudinal trends in obesity in the United States form the adolescence to the third decade of life. Obesity (Silver Spring) 2010; 18(9): 1801-4.

[17] Trujillo IJ, García RJ, Del Pozo SV, et al. Trends from 1995 to 2006 in the prevalence of self-reported cardiovascular risk factors among elderly Spanish diabetics. Diabetes Metab 2010; 36(1): 2935.

[18] Fourth Joint Task Force of the European Society of Cardiology and Other Societies on Cardiovascular Disease Prevention in Clinical Practice. European guidelines on cardiovascular disease prevention in clinical practice: executive summary. Eur Heart J 2007; 28: 2375-414.

[19] Law MR, Wald NJ, Morris JK, Jordan RE. Value of low dose combination treatment with blood pressure lowering drugs: analysis of 354 randomised trials. Br Med J 2003; 326: 1427-34.

[20] Safar ME. Pulse pressure, arterial stiffness and wave reflections (augmentation index) as cardiovascular risk factors in hypertension. Ther Adv Cardiovasc Dis 2008; 2: 13-4.

Received: February 18, 2011

Revised: April 21, 2011

Accepted: April 22, 2011

(C) Varis et al.; Licensee Bentham Open.

This is an open access article licensed under the terms of the Creative Commons Attribution Non-Commercial License (http: //creativecommons.org/licenses/by$\mathrm{nc} / 3.0 /$ ), which permits unrestricted, non-commercial use, distribution and reproduction in any medium, provided the work is properly cited. 